\title{
Article
}

\section{The Role of the Human Factor in Marine Accidents}

\author{
Nermin Hasanspahić ${ }^{1, *(\mathbb{D})}$, Srđan Vujičić ${ }^{1}$, Vlado Frančić $^{2}$ and Leo Čampara ${ }^{1}$ \\ 1 Maritime Department, University of Dubrovnik, 20000 Dubrovnik, Croatia; srdjan.vujicic@unidu.hr (S.V.); \\ leo.campara@unidu.hr (L.Č.) \\ 2 Faculty of Maritime Studies, University of Rijeka, 51000 Rijeka, Croatia; vfrancic@pfri.hr \\ * Correspondence: nermin.hasanspahic@unidu.hr
}

Citation: Hasanspahić, N.; Vujičić, S.; Frančić, V.; Čampara, L. The Role of the Human Factor in Marine Accidents. J. Mar. Sci. Eng. 2021, 9 , 261. https://doi.org/10.3390/ jmse9030261

Academic Editor: Spyros Hirdaris

Received: 11 February 2021

Accepted: 24 February 2021

Published: 1 March 2021

Publisher's Note: MDPI stays neutral with regard to jurisdictional claims in published maps and institutional affiliations.

Copyright: (c) 2021 by the authors. Licensee MDPI, Basel, Switzerland. This article is an open access article distributed under the terms and conditions of the Creative Commons Attribution (CC BY) license (https:// creativecommons.org/licenses/by/ $4.0 /)$.

\begin{abstract}
A common interest of all shipping industry stakeholders is safe and accident-free shipping. To reach that goal, one of the most important actions that can be done is to analyze previous marine accidents. It means finding causes of accidents and, based on the analysis results, implementing effective corrective measures that can help reduce such undesired events in the future and improve safety efforts in shipping. Since it is widely accepted that human error accounts for $80-85 \%$ of all marine accidents, the research was focused on the human factor analysis in marine accidents. In this paper, 135 marine accident reports recorded in the UK Marine Accident Investigation Branch (MAIB) database from 2010 to 2019 were analyzed. The analysis aimed to categorize causal factors and discover the ones that are the most common. The Human Factor Analysis and Classification System for Maritime Accidents (HFACS-MA) method was used to be able to do so. Furthermore, multiple linear regression was used to determine the relationship between the number of accidents and the most common HFACS-MA causal factors. The research revealed that the causes of marine accidents are primarily dependent on two human factor categories and confirmed that by influencing those human factors categories, the number of marine accidents could be reduced and shipping safety improved in general.
\end{abstract}

Keywords: human factor; marine accident analysis; maritime safety; HFACS-MA

\section{Introduction}

The shipping industry accounts for more than $90 \%$ of global world trade in goods, and as such, it is one of the world economy drivers [1]. The safety of ships at sea is the primary concern of all stakeholders. Lack of safety can induce loss of lives, environmental pollution, damage to cargo and vessel, and it needs to be avoided [2]. The International Maritime Organization (IMO) focused on improving safety onboard ships through different sets of rules, regulations, and requirements. Improvements are visible in ships' design, stability, propulsion, equipment, and human elements.

Even though ships' inspections are stringent and substandard ships are kept in detention or prohibited to continue with the operation, the number of marine accidents is still large [3]. Several catastrophic accidents occurred in the past decade, such as the sinking of container ship SS El Faro and cargo ship Cemfjord with the worst consequences-total loss and fatalities.

A marine accident, as per [4,5], is any marine casualty or incident. An accident does not include an intentional act or omission to cause harm to the safety of a vessel, persons, or the marine environment [4,5]. Accidents are usually not caused by a single mistake but by the chain of errors, or when all defenses, barriers, and safeguards are penetrated. To prevent such disasters in the future, reduce the number of marine accidents, and increase safety in the maritime sector, shipping stakeholders must find the root causes of accidents and implement adequate and efficient corrective, preventive measures.

Human error accounts for about $80-85 \%$ of all marine accidents [6]. Since new technologies have been introduced in maritime transport lately, some of the factors that can lead 
to human error are technology complacency and over-reliance on technology $[7,8]$. Human factors, shown as the basis of marine accidents, cover all actions revealing the relation between people and machines [9]. Human-machine interaction is an important safety aspect that needs to be nourished and transformed into the most vital safety link; it must not be marked as a weak link of maritime safety. A great deal of effort has been put into reducing the effect of human factors in marine accidents. For example, several international organizations, such as IMO, International Labour Organization (ILO), and International Association of Ship Classification Societies (IASCS), work diligently to prevent human error through their respective work domains. It is worth mentioning that the ISM Code is one of the most robust tools to combat human error in shipping.

As this paper aims to elucidate the role of human factors at various organization levels, reviewed maritime accident reports were analyzed using the HFACS-MA framework, shaped to fit for analysis of marine accidents precisely [10].

A few pieces of research used the HFACS method as an analysis tool for marine accidents. Chen et al. [10] analyzed marine casualties using the HFACS-MA framework. They adopted it from the original HFACS framework and shaped it to suit the analysis of marine casualties, specifically human and organizational factors. The why-because graph complemented the HFACS-MA framework, and the Herald of Free Enterprise accident was used to demonstrate the method. Chauvin et al. [1] analyzed collision at sea reports from MAIB (UK) and Transportation Safety Board (Canada) using HFACS. They adopted a method for usage in the maritime context. Research analysis showed that most of the collisions occurred due to decision errors. Schröder-Hinrichs et al. [11] reviewed 41 accident investigation reports concerning fires and explosions in machinery spaces onboard ships. The original HFACS method was adopted, slightly modified, and renamed to HFACS-MSS. Results of the research showed that the largest percentage of causal factors were preconditions for unsafe acts. Qiao et al. [12] proposed a comprehensive accident analysis model that integrates HFACS, Fuzzy Fault Tree Analysis (FTA), and Artificial Neural Networks (ANN) method. The study results showed that the ANN-based model could overcome FTA flaws and has possibilities for further improvement. Research that used HFACS methodology and statistical methods made by Yildirim et al. [13] identified that the most important causes of the accidents are unsafe acts and preconditions that generate those acts. The most frequent causes found were decision errors, resource management deficiencies, violations, skill-based errors, and miscommunication. Qiao et al. [14] introduced a new human factors analysis framework called the multi-dimensional analysis model of accident causes (MAMAC). The authors tested the proposed model on one marine accident from a sand carrier accident database in China and identified the top ten accident contributing events. Unsafe preconditions and unsafe supervision are recorded as the top two considerations for human factor analysis. One of the advantages of the proposed model is calculating the probability of failure of accidents induced by human factors. Marine-specific Error Producing Conditions (EPC) are produced in research done by Akyuz et al. [15]. The authors utilized a multi-dimensional approach that involved Majority Rule, HEART, HFACS, AHP methodology, and validation techniques. Celik and Cebi [16] developed an analytical HFACS based on a Fuzzy Analytical Hierarchy Process and identified the role of human errors in marine accidents. Chen [17] applied why-because analysis, HFACS-MA, and Grey Relational Analysis (GRA) to create a systematic analysis procedure divided into three phases. The proposed approach identifies the common human and organizational factors (HOF) among accidents without losing the context details of individual accidents. The authors used the proposed framework on five marine accidents, and analysis results showed $\mathrm{HOFs}$ and gave broad insight into each analyzed accident. Theophilus et al. [18] tried to improve the existing HFACS tool and proposed a novel method for the Oil and Gas Industry called HFACS-OGI. The research confirmed that their method is suitable for categorizing accidents and indicated that industry regulatory standards' failures would automatically create the preconditions 
for accidents. Existing literature confirmed the adequacy of using the HFACS to analyze human and organizational factors in marine accidents.

The accident causes determination model developed by Reason provided a methodology for understanding human error within a system. HFACS was developed to provide a tool for accident investigation complementing Reason's model [11]. Because HFACS was initially developed for analyzing military aviation accidents, several researchers have made adaptations to its framework. Chen et al. developed the HFACS-MA framework. It complies with IMO guidelines for investigating human factors in marine accidents and is in line with Reason's Swiss Cheese Model and Hawkins' SHEL model [10]. HFACS-MA methodology is comprised of five levels containing 21 human factor causal categories. The first level is unsafe acts, and it consists of errors and violations. The framework divides errors into skill-based errors, rule-based mistakes, and knowledge-based mistakes. Violations are divided into routine and exceptional violations. The second level consists of preconditions that include the SHELLO model developed by Chang and Wang [19]. Preconditions include software, hardware, environment, liveware, and condition of the operator. The environment is further divided into physical and technological. It depicts seafarers surroundings that affect the operator's actions, like written procedures, checklists, workplace, weather conditions (gale winds, tidal streams), navigating area conditions like canals, traffic separations schemes, Vessel Traffic Service (VTS) operation, and others, communication between seafarers and other persons included in the operation, fatigue, situational awareness, and others. The third level is unsafe supervision, and it is made up of four factors: inadequate supervision, planned improper operation, failure to correct the known problem, and supervisory violations. Organizational influences make up the fourth level of the framework. The level consists of resource management, organizational climate, and organizational process. The fifth level is external factors, which include legislation gaps, administration oversights, and design flaws. Table 1 describes each level category.

Table 1. Description of Human Factor Analysis and Classification System for Maritime Accidents (HFCAS-MA) causal categories.

\begin{tabular}{|c|c|}
\hline HFCAS-MA Causal Categories & Description \\
\hline \multicolumn{2}{|l|}{ External factors } \\
\hline Legislation Gaps (LG) & $\begin{array}{l}\text { It includes the shortcomings of existing rules or codes serving as guidelines to the } \\
\text { maritime industry stakeholders and relevant authorities }[10,20] \text {. }\end{array}$ \\
\hline Administration Oversights (AO) & $\begin{array}{l}\text { It includes failures of relevant authorities and organizations in implementing and } \\
\text { enforcing existing rules or codes and negligent performance of their duties [10]. }\end{array}$ \\
\hline Design Flaws (DF) & $\begin{array}{l}\text { Poor system design includes inadequate consideration of ergonomics and } \\
\text { maintenance of the system }[10,21] .\end{array}$ \\
\hline \multicolumn{2}{|l|}{ Organizational Influences } \\
\hline Resource Management (RM) & $\begin{array}{l}\text { A way of managing and allocating human and financial resources and equipment } \\
\text { necessary for the safe performance of daily tasks }[10,22,23] \text {. }\end{array}$ \\
\hline Organizational Climate (OC) & $\begin{array}{l}\text { A working atmosphere on ships includes onboard ship command structures, } \\
\text { policies, and culture }[10,22,23] .\end{array}$ \\
\hline Organizational Process (OP) & $\begin{array}{l}\text { The company's formal policy is implemented onboard ships and includes } \\
\text { shipboard operations, procedures, and crewmembers' oversight }[10,22,23] \text {. }\end{array}$ \\
\hline \multicolumn{2}{|l|}{ Unsafe Supervision } \\
\hline Inadequate Supervision (IS) & $\begin{array}{l}\text { The factor includes shipboard leadership failures in the crew's supervision while } \\
\text { performing a particular operation and thus may cause an unsafe situation or an } \\
\text { error, including training, guidance, and other aspects }[1,10,23,24] \text {. }\end{array}$ \\
\hline Planned Inappropriate Operation (PIO) & $\begin{array}{l}\text { The factor includes shipboard leadership failures in planning operations related to } \\
\text { improper or inappropriate crew scheduling, inadequate operational planning of } \\
\text { the operation, or operation assignment without clarifying essential data for the } \\
\text { shipboard operation's safe-conduct }[1,10,23,24] .\end{array}$ \\
\hline
\end{tabular}


Table 1. Cont.

\section{HFCAS-MA Causal Categories}

Failure to Correct Known Problem (FCKP)

Supervisory Violations (SV)

Preconditions (SHEL)

Condition of Operator(s) (CO)

Software (S)

Hardware $(\mathrm{H})$

Physical Environment (PE)

Technological Environment (TE)

Liveware (L)

Unsafe Acts

Skill-Based Errors (SBE)

It includes unintentional actions, which include failures that involve
(slips) and failures that involve memory (lapses) $[10,25]$.

It includes mistakes due to the choice of wrong rules due to the wrong perception of the situation or mistakes caused due to not applying the correct rule at all

Rule-Based Mistakes (RBM) $[10,27]$.

It includes factors that reduce a person's performance ability and includes mental, physiological, and physical preconditions, such as alcoholism, illness, knowledge, fatigue, complacency, and others $[10,23,25]$.

It includes a lack of formal instructions from the company or shipboard leadership such as written processes, policies, check-lists, operating manuals, instructions, charts, maps, and computer programs. [10,25,26].

It includes the workplace's physical characteristics such as workstation equipment, control modes, displays, visibility from the workstation, and others $[10,25]$.

It includes natural forces that can influence individuals' decisions, such as gale winds, tidal streams, sea currents, waves, and fog, thus creating unsafe situations or human error $[10,25]$.

It includes artificial structures such as breakwaters, waterways, canals, locks, maritime traffic control surveillance, and others [10,25].

It includes lack of communication or inadequate and incomplete communication between persons on board, such as communication between the navigation team, the engine room, the navigation bridge, the pilot and the navigation team, and the ship and the shore $[10,25]$.

It includes mistakes that happen due to lack of knowledge of person operating or inadequate application of knowledge acquired [10,27].

It includes actions that occur because seafarers do not adhere to standard work procedures and take shortcuts mostly due to poorly defined work practices or poor Routine Violations (RV) design and, for example, try to speed up the process, and then the error occurs due to overconfidence in their abilities or inexperience. Governing authorities often tolerate these actions, and they tend to become habitual $[10,25,27,28]$.

Exceptional Violations (EV)

It includes intentionally ignoring safety rules to get the job done and usually do not become habitual $[10,25]$.

The objectives of this paper are to identify the role of the human factor in marine accidents, determine the most common causal factors according to the HFACS-MA taxonomy, and to find which of the causal factors could be used as predictors of marine accidents, i.e., which have a significant effect on the number of accidents. Acting on reducing predicting factors can help reduce the number of marine accidents and improve shipping safety.

Section 2 includes methodology adopted in the paper. Section 3 presents the results and discussion of the HFACS-MA framework, and Section 4 presents the results and discussion of multiple linear regression applied on results of the HFACS-MA framework. Conclusions are presented in Section 5. 


\section{Methodology}

The research was divided into three phases: 1 . selecting marine accident reports, 2 . analysis of selected reports using HFACS-MA methodology, and 3. determining most frequent accident causal factors and applying multiple regression analysis to find which factors could be used as predictors of marine accidents (Figure 1).

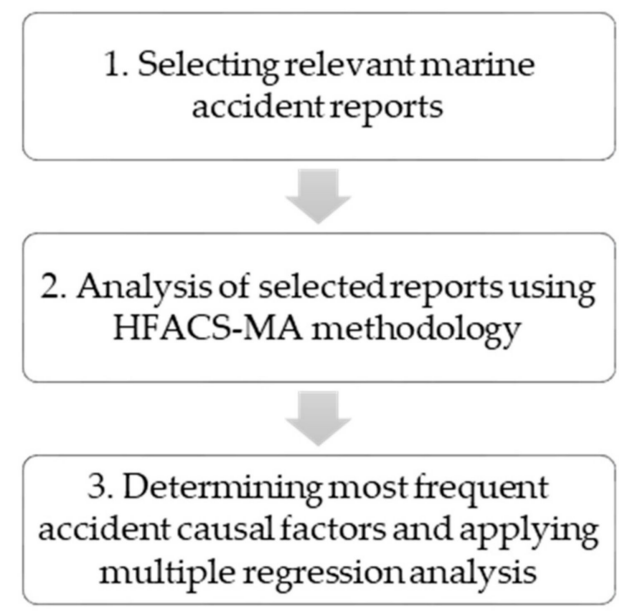

Figure 1. Research phases.

The first phase of the research presented in this paper was selecting relevant marine accident reports that occurred in the period from 1 January 2010 to 31 December 2019. The period was selected because it includes a new edition of the ISM Code in 2010, including the latest amendments in 2015, up to the present. The importance of amendments in 2010 is amendments to Section 7-Development of plans for shipboard operations. The authors used the Marine Accident Investigation Board (MAIB) UK database to select accident reports since they include human factor causes based on a model of accident causation developed by Reason [26]. Reports including merchant ships 100 gross tons or over were included in the study, while authors excluded reports concerning only ships under 100 gross tons, fishing vessels, and pleasure crafts from the study since the aim of the paper is to reveal the role of the human factor in the causation of accidents on merchant ships. This paper intends not to re-investigate reviewed accidents but obtain and evaluate human factors that cause marine accidents. The authors found a total of 135 completed relevant marine accident reports investigated by MAIB, and those reports were selected for further analysis during the collection phase.

The next research phase was the analysis of selected reports using HFACS-MA methodology. Human factors were obtained as objectively as possible by examining the analysis, conclusion, and recommendation sections of the MAIB accident report. Coding of accidents contributing factors gained from reviewed reports by HFACS-MA causal categories was done by two research team members that can be considered experts with a marine background as master mariners, trained on accident investigation, and familiar with using the methodology. Final decisions on causal categories were based on consensus. Due to their expertise in the field, it can be considered that usage of HFACS-MA during the analysis of marine accidents was more practical and authentic. A comprehensive list of accident contributing factors by HFACS-MA categories was developed as a result of the coding process.

The next research phase was determining the most frequent accident contributing factors. To set up an accident prediction model based on HFACS-MA categories of contributing factors, the authors applied multiple regression analysis, a statistical analysis based method. The multiple regression analysis methods describe the relationship between a dependent variable and several independent (explanatory) ones [29]. It is a very effective 
method that can be used for predicting, forecasting, and error reduction [30]. The general multiple regression equation is:

$$
Y_{i}=\alpha+\beta_{1} x_{i 1}+\beta_{2} x_{i 2}+\ldots+\beta_{p} x_{i p}+e_{i} \text { for } i=1, \ldots n
$$

where $Y_{i}$ is the continuous response variable (dependent variable), $\alpha$ is an intercept parameter, $x_{i 1} \ldots x_{i p}$ is a set of explanatory variables, $\beta_{1} \ldots \beta_{p}$ are regression coefficients, and $e_{i}$ is the error term [31].

Programming language R (version 4.0.0 ×64) specialized for statistical analysis, data mining, and machine learning and RStudio (Desktop version 1.3.959) set of integrated tools designed to utilize the usage of $\mathrm{R}$, were used for statistical data analysis and modeling [32]. In the next section, the results of the analysis of reviewed marine accidents are presented.

\section{HFACS-MA Results and Discussion}

The HFACS-MA methodology for marine accident analysis identified 911 causal factors. It is important to emphasize that one accident can have multiple causal factor categories. Table 2 presents the review of 135 MAIB accident reports using HFACS-MA coding, where the frequency of each identified contributory factor category is given.

Table 2. Distribution of obtained HFACS-MA causal factor categories.

\begin{tabular}{cccc}
\hline & HFACS-MA Categories & $\mathbf{N}$ & $\mathbf{( \% )}$ \\
\hline \multirow{3}{*}{ External Factors } & Legislation Gaps & 18 & $2.0 \%$ \\
& Administration Oversights & 20 & $2.2 \%$ \\
& Design Flaws & 32 & $3.5 \%$ \\
\hline \multirow{3}{*}{ Organizational Influences } & Resource Management & 46 & $5.0 \%$ \\
& Organizational Climate & 103 & $11.3 \%$ \\
& Organizational Process & 70 & $7.7 \%$ \\
\hline \multirow{3}{*}{ Unsafe Supervision } & Inadequate Supervision & 63 & $6.9 \%$ \\
& Planned Inappropriate Operation & 49 & $5.4 \%$ \\
& Failure to Correct Known Problem & 25 & $2.7 \%$ \\
& Supervisory Violations & 13 & $1.4 \%$ \\
\hline \multirow{3}{*}{ Preconditions } & Condition of Operator(s) & 112 & $12.3 \%$ \\
& Software & 61 & $6.7 \%$ \\
& Hardware & 40 & $4.4 \%$ \\
& Physical Environment & 20 & $2.2 \%$ \\
& Technological Environment & 12 & $1.3 \%$ \\
& Liveware & 54 & $5.9 \%$ \\
\hline Total & Skill-Based (Slips and Lapses) Errors & 25 & $2.8 \%$ \\
& Rule-Based Mistakes & 41 & $4.5 \%$ \\
& Knowledge-Based Mistakes & 35 & $3.9 \%$ \\
& Routine Violations & 65 & $7.1 \%$ \\
& Exceptional Violations & 7 & $0.8 \%$ \\
\hline \multirow{2}{*}{ Unsafe Acts } & & 911 & $100 \%$ \\
\hline & & &
\end{tabular}

According to the analysis, the most common factor categories were Preconditions for Unsafe Acts, Organizational Influences, and Unsafe Acts.

\subsection{Preconditions for Unsafe Acts}

Preconditions for unsafe acts were identified as the most represented group of causal categories, with $32.7 \%$ of all contributory factors. The most represented group of secondlevel causal factor categories was Condition of Operator(s) with $12.3 \%$ of total factors. Some examples of the category from the reviewed reports are crew unprepared for emergencies and unfamiliar with using rescue slings, low situational awareness, overreliance on radar, functions impaired by alcohol, and limited knowledge about the matter. According to [33], 
fatigue, stress, health, non-technical skills, situation awareness, and cultural diversity could reduce an individual's ability to perform given tasks and thus lead to unsafe situations. Fatigue contributed to seven accidents analyzed in this paper. Seafarer fatigue is one of the most common factors and can be induced by various reasons such as long working hours, extended work, the short period of rest between working hours, vibrations, noise, stress, excessive workload, and ship's motion [34]. The impact of fatigue is amplified in short sea navigation and cases when ship manning is reduced, and bridge watchkeepers need to keep six on-six off watches [35]. Although International Labor Organization (ILO), through the Maritime Labor Convention (MLC) from 2006, introduced minimum hours of rest that all seafarers need to comply with, there are still cases where hours of rest are not complied with, or records are falsified. Another essential issue is drug or excessive alcohol consumption, which contributed to nine accidents analyzed. Kim et al. [36] found that alcohol intoxication significantly affects bridge watchkeepers' ability to handle the ship and increases mental workload. To prevent alcohol abuse on ships, Oil Companies International Marine Forum (OCIMF) recommended that shipping companies have written drug and alcohol policies onboard ships [37]. Although more stringent measures regarding alcohol abuse are enforced lately, such as "dry-ships ", human errors due to alcohol impairment still occur.

Another critical causal factor of this level was Software, which accounted for $6.7 \%$ of total factors. As Software includes a lack of written procedures from the company or shipboard leadership or not following those, it is in line with ISM Code Section 7 Development of plans for shipboard operations. Some of the examples of software casual factors from reviewed reports are: pitch and roll limits not readily available from ship's loading computer, training wall data not displayed on navigation chart or in publications, tidal stream data were insufficient to plan safe passage of ships, maintenance instructions unavailable, the towing manual was inadequate, and company policy did not give exact instructions of what information a cargo loading plan should include. According to [38], there are situations when written procedures and check-lists onboard ships are not helpful since they do not reflect an onboard situation or are not applicable. Such written documents that management expects to be followed by the ships' crews are essential for the safe performance of everyday operations, and they have to reflect actual conditions and apply to a specific ship since usually there are differences between same-company ships. If such documents, or computer software, are not applicable, it can lead to an unsafe condition and generate human errors. One of the ship's practical examples is a manual for specific equipment replaced with the new one still kept onboard a ship, and a manual for the new equipment not onboard a ship. Such obsolete manual can create confusion and induce human error during equipment handling. According to ISM, seafarers should immediately report such conditions and rectify them as soon as possible [7].

Liveware accounts for $5.9 \%$ of the total number of causal factors. As consistent and direct communication leads to a sense of trust between all maritime stakeholders and especially between crew onboard ships, communication is considered as one of the pillars of a healthy organization [39]. Inefficient and inadequate communication can lead to an unsafe condition and human error, which needs to be prevented. Some of the examples of Liveware factor from reviewed reports include the following: berthing plan not discussed with crewmembers before berthing, $\mathrm{C} / \mathrm{O}$ did not inform the master that ship needs repositioning, confusing communication between bridge teams on two ships in a close quarters situation, passage plan key points not discussed between pilots and ship's bridge team, poor communication between duty engineer and bridge team after contact and insufficient communication between ship and launch. Shipboard leadership should encourage open and direct communication between crewmembers and external parties such as pilots, tugboat masters, or VTS officers. 


\subsection{Organizational Influences}

Causal factors included in the HFACS-MA methodology fourth level accounts for $24.1 \%$ of the total number of the causal factor. Organizational Climate (11.3\%) and Organizational Process $(7.7 \%)$ were the most represented causal factors at this level.

Organizational Climate can be described as the way things are done onboard a ship. It includes culture, policies, and structure, and it is affected by various factors, such as national culture, leadership, and knowledge of the individual. Organizational Climate examples from reviewed reports include mobile phones' usage during bridge watch, lousy attitude towards safety measures, bridge team not participating in pilotage, and weak safety culture. The shipboard leadership (master) role is vital in constructing a sound safety culture onboard ship [40]. To include all crewmembers in the onboard safety system and create a safe organizational climate, company shore management should ensure that masters have adequate leadership knowledge, provide shore support at all times and develop a system that will ensure adequate onboard management.

Organizational Process includes incomplete or inadequate safety-related policies such as Safety Management System (SMS). Some of the examples from reviewed reports are: risk Assessment for discharge operation did not include all actions needed to be performed, and thus not all risks were included, inadequate guidance and support for masters, inadequate SMS and emergency release of towing hook not included in monthly drill program. The company should prepare ship and company specific SMS, and it should reflect procedures that apply to it. According to [38], it was found that some SMS found onboard ships are not applicable and do not reflect the onboard situation. It looked like persons without seagoing experience prepared them. Such conditions onboard can quickly create an unsafe condition that reflects the organizational influence on an accident.

\subsection{Unsafe Acts}

Unsafe Acts account for $19.1 \%$ of the total number of causal factors categories. Routine Violations with $7.9 \%$ are the most represented group within this level. Some examples found in reviewed reports are: the navigating bridge left unattended during navigation, sound signals not used in reduced visibility, crewmembers climbing on top of the cargo without installed safety measures, non-compliance with company rules for passage planning, and deck gate used routinely for pilot boarding although it was not a part of pilot boarding station. Routine violations usually occur when crewmembers want to complete a particular operation as soon as possible due to some reasons and start cutting corners. At that moment, the original plan's deviation that took into account the risks associated with it starts. Cutting corners usually demands the original plan's change and introduces new risks that are not assessed while increasing the possibility of human error. Inadequate and inapplicable check-lists or work procedures onboard ships also leads to routine violations since the formal routine cannot be executed or is impractical to be followed [38].

Rule-Based Mistakes account for $4.5 \%$ of the total number of causal factors categories and include crewmembers' mistakes in connection with choice or application of the wrong rule in developing hazardous situations or not applying the correct rule at all. Some examples include crossing the Traffic Separation Scheme contrary to the International Regulations for Preventing Collision at Sea, using VHF radio for collision avoidance purposes, and the main engine not tested before port passage.

Most frequent variables affecting the prevalence of accidents were identified, and according to the results of the analysis, six variables or contributory factors make $52 \%$ of the total percentage of all contributory factors (Table 2). The other 15 contributory factors' effect can be considered weak, and the authors did not take them into account for further evaluation.

\section{Multiple Linear Regression Results and Discussion}

Six contributory factors $\left(x_{1}\right.$ to $\left.x_{6}\right)$ derived from the analysis that made $52 \%$ of all contributory factors were arranged in a table to enable easier data handling (Table 3). The 
most frequent marine accidents' contributory factors were included in multiple linear regression analysis. Six factors out of 21 were taken for analysis. Those six contributory factors are taken for analysis because they account for $52 \%$ of all accident's contributory factors. They could be considered strong predictors of marine accidents and sufficient for modeling. The other 15 contributory factors' effect is considered weak since all of them made only $48 \%$ of the accident's contributory factors together, and they were not considered for further evaluation. Multiple linear regression was used to derive a predictive model of the number of accidents resulting from those determined most frequent contributory factors. The number of accidents was set as a dependent variable $(\mathrm{Y})$, and most frequent HFACS-MA causal factors obtained from analysis as explanatory variables. Data from the year 2019 were discarded since only one accident was investigated and recorded in the MAIB database when the data analysis was performed.

Table 3. Distribution of most frequent causal factors categories by years.

\begin{tabular}{|c|c|c|c|c|c|c|c|}
\hline Year & $\begin{array}{l}Y=\text { Number } \\
\text { of Accidents }\end{array}$ & $\begin{array}{c}x_{1}= \\
\text { Condition of } \\
\text { Operator(s) }\end{array}$ & $\begin{array}{c}x_{2}= \\
\text { Organizational } \\
\text { Climate }\end{array}$ & $\begin{array}{c}\mathrm{x}_{3}= \\
\begin{array}{c}\text { Organizational } \\
\text { Process }\end{array}\end{array}$ & $\begin{array}{c}\mathbf{x}_{4}=\text { Routine } \\
\text { Violations }\end{array}$ & $\begin{array}{c}\quad x_{5}= \\
\text { Inadequate } \\
\text { Supervision }\end{array}$ & $\begin{array}{c}x_{6}= \\
\text { Software }\end{array}$ \\
\hline 2010 & 17 & 9 & 11 & 12 & 7 & 8 & 9 \\
\hline 2011 & 25 & 16 & 18 & 7 & 6 & 12 & 12 \\
\hline 2012 & 14 & 13 & 14 & 10 & 7 & 5 & 6 \\
\hline 2013 & 18 & 18 & 14 & 8 & 5 & 7 & 7 \\
\hline 2014 & 17 & 10 & 11 & 7 & 4 & 5 & 6 \\
\hline 2015 & 13 & 17 & 16 & 9 & 8 & 11 & 4 \\
\hline 2016 & 12 & 13 & 9 & 5 & 16 & 7 & 7 \\
\hline 2017 & 9 & 8 & 4 & 7 & 5 & 3 & 4 \\
\hline 2018 & 9 & 7 & 5 & 4 & 6 & 4 & 6 \\
\hline
\end{tabular}

A correlation matrix developed in $\mathrm{R}$ was used to verify the dependence between explanatory variables. Correlation coefficients between the explanatory variables are shown in Table 4.

Table 4. Explanatory variables correlation matrix.

\begin{tabular}{|c|c|c|c|c|c|c|}
\hline & $\begin{array}{l}\text { Condition of } \\
\text { Operator(s) } \\
\text { (CO) }\end{array}$ & $\begin{array}{c}\text { Organizational } \\
\text { Climate (OC) }\end{array}$ & $\begin{array}{c}\text { Organizational } \\
\text { Process (OP) }\end{array}$ & $\begin{array}{c}\text { Routine } \\
\text { Violations } \\
\text { (RV) }\end{array}$ & $\begin{array}{c}\text { Inadequate } \\
\text { Supervision } \\
\text { (IS) }\end{array}$ & $\begin{array}{c}\text { Software } \\
\text { (S) }\end{array}$ \\
\hline $\begin{array}{l}\text { Condition of } \\
\text { Operator(s) }\end{array}$ & 1 & & & & & \\
\hline Organizational Climate & 0.8369 & 1 & & & & \\
\hline Organizational Process & 0.1884 & 0.4518 & 1 & & & \\
\hline Routine Violations & 0.1444 & -0.0470 & -0.2251 & 1 & & \\
\hline $\begin{array}{l}\text { Inadequate } \\
\text { Supervision }\end{array}$ & 0.7074 & 0.8211 & 0.2780 & 0.1853 & 1 & \\
\hline Software & 0.2184 & 0.4729 & 0.1093 & 0.0314 & 0.5545 & 1 \\
\hline
\end{tabular}

From the correlation matrix, it can be concluded that there is a significant relationship between some of the explanatory variables. It means that it is most likely not possible to proceed with modeling, including all variables, and it is necessary to exclude some. To ascertain conclusions derived from Table 4, a scatterplot diagram matrix of explanatory variables data was obtained before doing further tests in $\mathrm{R}$ (Figure 2). 


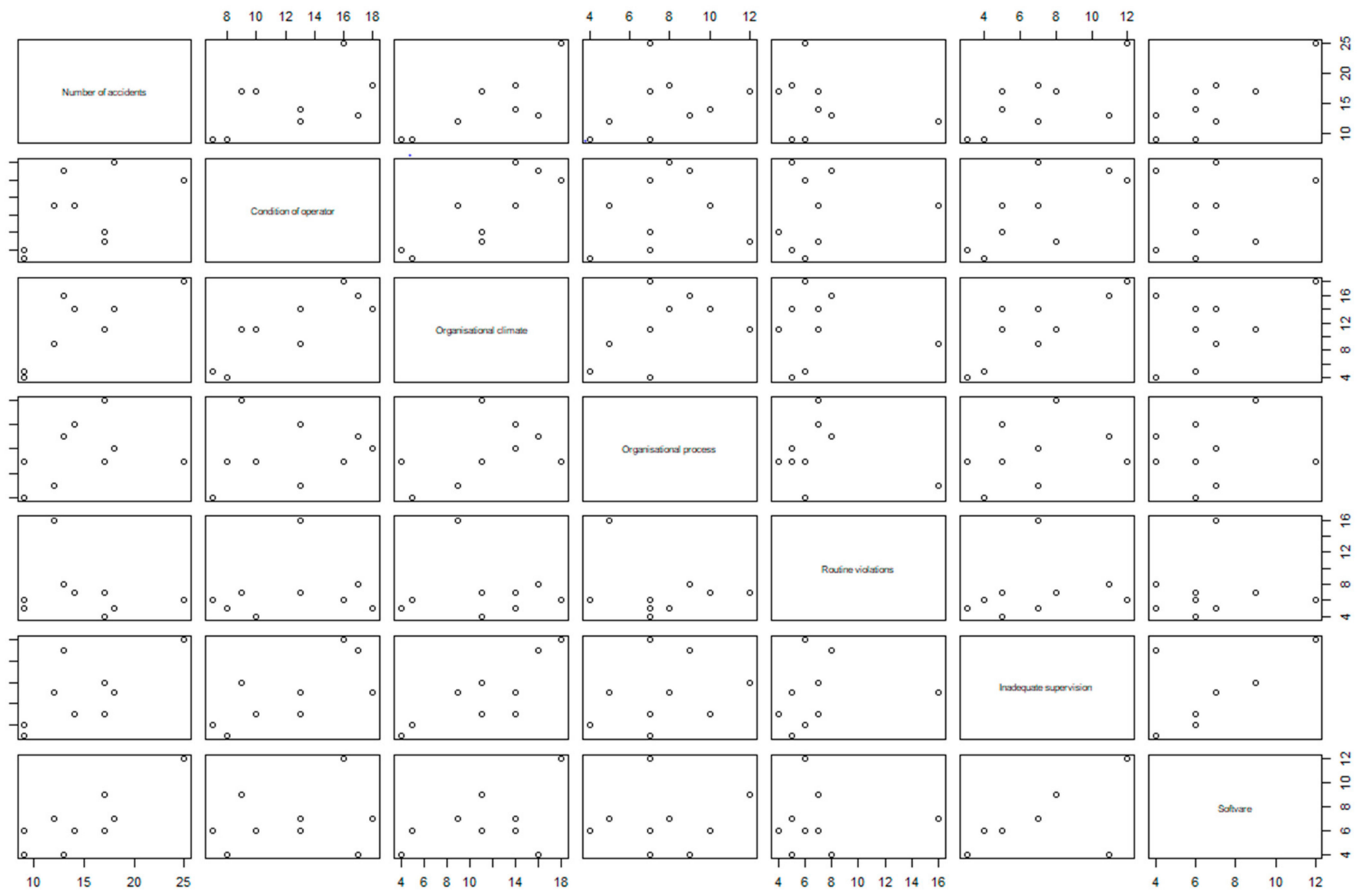

Figure 2. Scatterplot diagram matrix of explanatory variables.

Each scatterplot in the matrix presents the relationship between a pair of variables, enabling many relationships to be visualized in one chart. The individual variables are shown in a diagonal line from top left to bottom right. Then each variable is plotted against each other. For example, the third box from the left in the sixth row is an individual scatterplot of Organizational Climate and Inadequate Supervision, with Organizational Climate as the $X$-axis and Inadequate Supervision as the $Y$-axis. This same plot is reproduced in the second box from the right in the third row. Basically, the boxes on the upper right side from the scatterplot's diagonal line mirror the lower left side plots. The scatterplot diagram matrix shows the inconclusive explanatory effect of some individual variables, and there is a need to continue with further testing of the initial model with six explanatory variables. As the goal of the research is to obtain an accident number prediction model dependent on HFACS-MA contributory factors, it is necessary to determine if there is a significant relationship between the dependent and explanatory variables, and the following null hypotheses have been tested: $H_{0}: \beta_{1}=\beta_{2}=\beta_{3}=\beta_{4}=\beta_{5}=\beta_{6}=0$ at $\alpha=0.05$. Table 5 depicts the results of the multiple linear regression test in $\mathrm{R}$. 
Table 5. Results of multiple linear regression of initial model.

\begin{tabular}{|c|c|c|c|c|c|c|c|c|c|}
\hline Residuals & 1 & 2 & 3 & 4 & 5 & 6 & 7 & 8 & 9 \\
\hline & & -0.0875 & -1.3866 & 0.0161 & 2.3696 & -0.3255 & 0.7267 & 0.5551 & -1.9484 \\
\hline \multicolumn{10}{|l|}{ Coefficients } \\
\hline & Estimate $(\beta)$ & Std. Err. & t value & $\operatorname{Pr}(>|t|)$ & & & & & \\
\hline Intercept $(\alpha)$ & 2.3230 & 5.4851 & 0.424 & 0.713 & & & & & \\
\hline $\mathrm{CO}$ & 0.1609 & 0.5100 & 0.316 & 0.782 & & & & & \\
\hline OC & 0.4497 & 0.5878 & 0.765 & 0.524 & & & & & \\
\hline $\mathrm{OP}$ & -0.0205 & 0.4607 & -0.044 & 0.969 & & & & & \\
\hline RV & -0.3381 & 0.2864 & -1.181 & 0.359 & & & & & \\
\hline IS & -0.1136 & 0.5809 & -0.196 & 0.863 & & & & & \\
\hline$S$ & 1.3025 & 0.4854 & 2.683 & 0.115 & & & & & \\
\hline \multicolumn{5}{|c|}{ Residual standard error: 2.479 on 2 degrees of freedom (DF) } & \multicolumn{3}{|c|}{ Multiple $R^{2}: 0.9394$} & & \\
\hline \multicolumn{3}{|c|}{ Adjusted $R^{2}: 0.7577$} & \multicolumn{3}{|c|}{ F-statistic: 5.169 on 6 and $2(\mathrm{DF})$} & \multicolumn{2}{|c|}{$p$-value: 0.1709} & & \\
\hline
\end{tabular}

Estimates $(\beta)$, standard errors, and Wald (t-ratio) tests for each parameter are presented in Table 5.

As $\operatorname{Pr}(>|t|)$ and the $p$-value was 0.1709 , we could not reject $\mathrm{H}_{0}$. Since $\mathrm{H}_{0}$ could not be rejected, it was necessary to perform further tests and reduce the number of explanatory variables in the model. Hence, it was necessary to determine a significant relationship between individual explanatory variables and the dependent variable. In order to do those, the following null hypotheses were tested: $\mathrm{H}_{0,1}: \beta_{1}=0 ; \mathrm{H}_{0,2}: \beta_{2}=0 ; \mathrm{H}_{0,3}: \beta_{3}=0 ; \mathrm{H}_{0,4}: \beta_{4}=0$; $\mathrm{H}_{0,5}: \beta_{5}=0 ; \mathrm{H}_{0,6}: \beta_{6}=0$ at $\alpha=0.05$. Table 6 presents the results of individual simple linear regression on all six explanatory variables.

Table 6. Initial explanatory variables simple linear regression.

\begin{tabular}{|c|c|c|c|c|c|c|}
\hline Residuals & Min & $\mathrm{Q}_{1}$ & Median & $\mathrm{Q}_{3}$ & Max & \\
\hline $\mathrm{CO}_{\mathrm{R}}$ & -5.012 & -2.989 & -1.335 & 3.673 & 7.657 & \\
\hline $\mathrm{OC}_{\mathrm{R}}$ & -5.7864 & -0.9401 & 0.2358 & 2.3895 & 4.5432 & \\
\hline $\mathrm{OP}_{\mathrm{R}}$ & -5.463 & -2.741 & -1.185 & 2.537 & 10.537 & \\
\hline $\mathrm{RV}_{\mathrm{R}}$ & -6.5771 & 1.5991 & 0.0088 & 2.0749 & 9.7489 & \\
\hline $\mathrm{IS}_{\mathrm{R}}$ & -6.4941 & -2.6528 & 0.8665 & 2.9866 & 4.3858 & \\
\hline $\mathrm{S}_{\mathrm{R}}$ & -4.5897 & -1.6009 & 0.4103 & 2.7399 & 3.4103 & \\
\hline \multicolumn{7}{|l|}{ Coefficients } \\
\hline & Estimate $(\beta)$ & Std. Err. & t value & $\operatorname{Pr}(>|t|)$ & & \\
\hline Intercept $(\alpha)$ & 6.6355 & 5.0942 & 1.303 & 0.234 & Res. std. err: 4.532 on 7 DF & Multiple $R^{2}: 0.2914$ \\
\hline \multirow[t]{2}{*}{$\mathrm{CO}$} & 0.6692 & 0.3945 & 1.696 & 0.134 & Adjusted $R^{2}: 0.1901$ & $p$-value: 0.133 \\
\hline & & & \multicolumn{4}{|c|}{ F-statistic: 2.878 on 1 and 7 DF } \\
\hline Intercept $(\alpha)$ & 5.4235 & 3.0184 & 1.797 & 0.1154 & Res. std. err: 3.324 on 7 DF & Multiple $R^{2}: 0.6188$ \\
\hline \multirow[t]{2}{*}{ OC } & 0.8352 & 0.2477 & 3.371 & 0.0119 & Adjusted $R^{2}: 0.5644$ & $p$-value: 0.0119 \\
\hline & & & \multicolumn{4}{|c|}{ F-statistic: 11.37 on 1 and 7 DF } \\
\hline Intercept $(\alpha)$ & 9.9907 & 5.9139 & 1.689 & 0.135 & Res. std. err: 5.117 on 7 DF & $\begin{array}{c}\text { Multiple R }^{2} \text { : } \\
0.09657\end{array}$ \\
\hline \multirow[t]{2}{*}{$\mathrm{OP}$} & 0.6389 & 0.7386 & 0.865 & 0.416 & Adjusted $\mathrm{R}^{2}:-0.03249$ & $p$-value: 0.4157 \\
\hline & & & & & F-statistic: 0.7482 on 1 and $7 \mathrm{DF}$ & \\
\hline
\end{tabular}


Table 6. Cont.

\begin{tabular}{|c|c|c|c|c|c|c|}
\hline Intercept $(\alpha)$ & 17.2070 & 4.1000 & 4.197 & 0.00405 & Res. std. err: 5.24 on 7 DF & $\begin{array}{c}\text { Multiple } \mathrm{R}^{2} \text { : } \\
0.05284\end{array}$ \\
\hline \multirow[t]{2}{*}{ RV } & -0.3260 & 0.5216 & -0.625 & 0.55183 & Adjusted $\mathrm{R}^{2}:-0.08246$ & $p$-value: 0.5518 \\
\hline & & & \multicolumn{4}{|c|}{ F-statistic: 0.3905 on 1 and $7 \mathrm{DF}$} \\
\hline Intercept $(\alpha)$ & 7.1721 & 3.4043 & 2.107 & 0.0731 & Res. std. err: 3.945 on 7 DF & Multiple $\mathrm{R}^{2}: 0.4632$ \\
\hline \multirow[t]{2}{*}{ IS } & 1.1202 & 0.4558 & 2.458 & 0.0436 & Adjusted $R^{2}: 0.3865$ & $p$-value: 0.04362 \\
\hline & & & \multicolumn{4}{|c|}{ F-statistic: 6.039 on 1 and 7 DF } \\
\hline Intercept $(\alpha)$ & 3.5673 & 3.0956 & 1.152 & 0.28700 & Res. std. err: 3.038 on 7 DF & Multiple $R^{2}: 0.6815$ \\
\hline \multirow[t]{2}{*}{$S$} & 1.6704 & 0.4316 & 3.870 & 0.00613 & Adjusted $R^{2}: 0.636$ & $p$-value: 0.006129 \\
\hline & & & \multicolumn{4}{|c|}{ F-statistic: 14.98 on 1 and 7 DF } \\
\hline
\end{tabular}

Since $p$-values for Organizational Climate (0.0119) and Software (0.006129) were much less than 0.05 , the null hypotheses for these two variables could be rejected. According to the individual tests shown in Table 6, explanatory variables Organizational Climate and Software have the most effect on the dependent variable Number of accidents. Thus, it was necessary to adopt a multiple linear regression model with those two explanatory variables. It was again necessary to determine whether there is a significant relationship between the dependent and explanatory variables by testing the null hypothesis: $\mathrm{H}_{0}: \beta_{2}=\beta_{6}=0$ at $\alpha=0.05$. Table 7 presents the results of the test.

Table 7. Multiple linear regression of the two-factor model.

\begin{tabular}{|c|c|c|c|c|c|c|}
\hline Residuals & Min & $\mathrm{Q}_{1}$ & Median & $\mathrm{Q}_{3}$ & Max & \\
\hline & -1.8872 & -1.4146 & -0.3349 & 1.3682 & 3.2111 & \\
\hline \multicolumn{7}{|l|}{ Coefficients } \\
\hline & Estimate $(\beta)$ & Std. Err. & t value & $\operatorname{Pr}(>|t|)$ & & \\
\hline Intercept $(\alpha)$ & 0.7364 & 2.2019 & 0.334 & 0.7494 & Res. std. err: 1.983 on 6 DF & Multiple $R^{2}: 0.8838$ \\
\hline $\mathrm{OC}$ & 0.5419 & 0.1677 & 3.231 & 0.0179 & Adjusted $R^{2}: 0.845$ & $p$-value: 0.001571 \\
\hline $\mathrm{S}$ & 1.1820 & 0.3196 & 3.698 & 0.0101 & F-statistic: 22.81 on 2 and 6 DF & \\
\hline
\end{tabular}

As the $p$-value is much less than 0.05 ( $p$-value: 0.001571 ), the null hypothesis was rejected. Hence, there is a significant relationship between the variables in the multiple linear regression model.

The multiple linear regression model equation derived from the test can be used as a predictive model for the future number of accidents and shows that contributory factors Organizational Climate and Software have a major effect on the number of accidents in shipping reads:

$$
\mathrm{Y}=0.7364+0.5419 \times \mathrm{OC}+1.1820 \times \mathrm{S}
$$

where OC is Organizational Climate and $\mathrm{S}$ is Software. These two variables can explain $88.4 \%$ variability of the data.

If dependent variables Organizational Climate and Software are acted upon, and their average values are reduced, the number of accidents would be reduced, and maritime safety would be improved. Average annual values of variables were derived from the number of contributory factors between 2010 and 2018. Table 8 presents a drop in marine accidents related to reducing variables Organizational Climate and Software values. 
Table 8. Effect of explanatory variables values reduction on the number of marine accidents.

\begin{tabular}{ccccccc}
\hline & Average & \multicolumn{3}{c}{ Reduction Percentage of Dependent Variables } \\
\cline { 3 - 7 } & Annual Value & $\mathbf{1 0 \%}$ & $\mathbf{2 5 \%}$ & $\mathbf{5 0 \%}$ & $\mathbf{7 5 \%}$ & $\mathbf{1 0 0 \%}$ \\
\hline $\begin{array}{c}\text { Organizational } \\
\text { Climate }\end{array}$ & 11 & 10 & 8 & 6 & 3 & 0 \\
\hline Software & 7 & 6 & 5 & 3 & 2 & 0 \\
\hline $\begin{array}{c}\text { Annual Number of } \\
\text { Marine Accidents }\end{array}$ & 15 & 13 & 11 & 8 & 4 & 1 \\
\hline
\end{tabular}

As shown in Table 8, reducing contributory factors can induce a significant drop in the number of marine accidents. If contributory factors were reduced by $25 \%$, it would result in a $27 \%$ drop in marine accidents.

Furthermore, it was necessary to verify that the derived model has no significant heteroscedasticity, multicollinearity, and autocorrelation. A studentized Breusch-Pagan test was performed to check the model for significant heteroscedasticity. Authors used the Variable Inflation Factors (VIF) method to test the multicollinearity and Durbin-Watson test to check autocorrelation. Table 9 shows the results of the tests performed in R.

Table 9. Two-factor model heteroscedasticity, multicollinearity, and autocorrelation test.

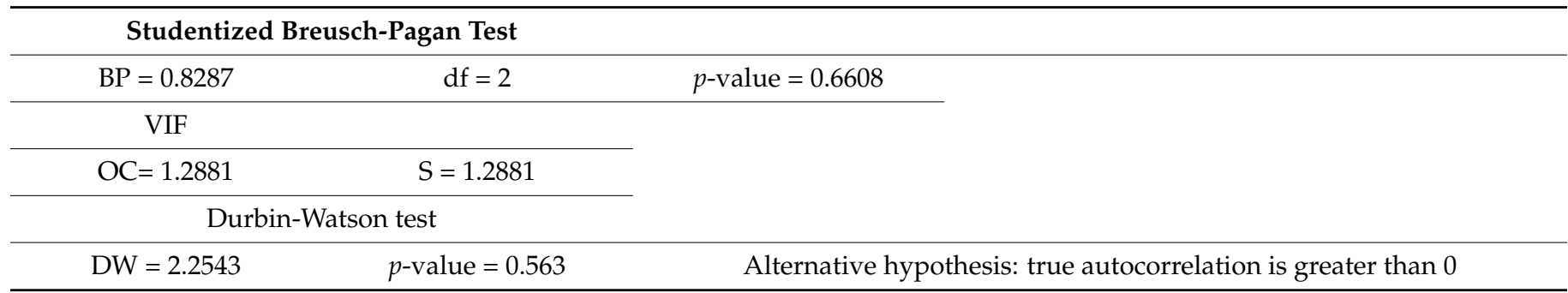

Data from Table 9 confirmed no significant heteroscedasticity, multicollinearity, and autocorrelation, and the derived model could be accepted.

\section{Conclusions}

This study focused on the effect of the human factor and its role in marine accidents. To better understand its effect on shipping, the authors used the HFACS-MA framework to analyze marine accident reports from the MAIB database in the last decade. The analysis confirmed that the human factor significantly affects the causation of marine accidents, and there could be multiple benefits from its reduction. One of this paper's main goals was discovering the most common human factor categories causing marine accidents and establishing their relationship. Condition of Operator(s) was the most common contributory factor category identified, followed by Organizational Climate and Organizational Process. The analysis results gave the most common contributory human factors that fit into a model using multiple linear regression. Since there was a significant relationship between some of the explanatory variables (contributory factors) and no significant relationship between all six explanatory variables and the dependent variable, the initial model had to be rejected. Significant relationships between individual explanatory variables and the dependent variable were tested and found that only two variables, namely Organizational Climate and Software, have a significant relationship with the dependent variable Number of accidents. The multiple linear regression model was developed with these two variables. The results obtained confirmed that the model is valid. There was a significant relationship between the independent and dependent variables, and there was no significant heteroscedasticity, multicollinearity, and autocorrelation. 
As shown by multiple linear regression, these two categories of contributory human factors significantly affect marine accidents. To increase safety and reduce the number of accidents, maritime industry stakeholders must act upon these factors. Additional shore management efforts in developing guidelines for masters and their crews for creating adequate safety climate could improve the Organizational climate onboard ships. Shipboard senior officers should receive training and guidance to implement measures that will allow the development of just culture onboard ships. To act upon the Software category of causal factors, shore management and shipboard crews must be included. Seafarers should report inadequate or inapplicable check-lists or work procedures to the company, and shore management should create adequate and applicable ship specific check-lists or procedures as corrective actions. The creation of such documents should be left on experts with maritime backgrounds, and onboard ship evaluation should be used as an adequacy measurement tool. As Organizational climate and Software have a significant effect on the number of marine accidents, adequate measures for reducing these two categories of causal factors could improve maritime safety. A reduction in $10 \%$ of these contributory factors could reduce the number of marine accidents by $13 \%$.

This study's limitation is a relatively small number of marine accidents reviewed since only 135 accident reports were selected as relevant for analysis according to research parameters. As this study is conducted on all types of merchant ships, future research will be done on specific ship types to discover a relationship between ship types and contributing human factors. Other databases containing marine accidents will be included in selecting relevant accident reports to increase the number of reports for review and analysis.

Author Contributions: Conceptualization, N.H. and S.V.; methodology, N.H.; Software, N.H.; validation, N.H., S.V., V.F. and L.Č.; formal analysis, N.H. and V.F.; investigation, N.H.; data curation, N.H. and S.V.; writing—original draft preparation, N.H.; writing—review and editing, N.H., S.V., V.F. and L.Č.; visualization, N.H.; supervision, N.H. and V.F. All authors have read and agreed to the published version of the manuscript.

Funding: This research received no external funding.

Institutional Review Board Statement: Not applicable.

Informed Consent Statement: Not applicable.

Data Availability Statement: Publicly available datasets were analyzed in this study. These data can be found here: (https:/ / www.gov.uk/maib-reports (accessed on 11 February 2021)).

Conflicts of Interest: The authors declare no conflict of interest.

\section{References}

1. Chauvin, C.; Lardjane, S.; Morel, G.; Clostermann, J.-P.; Langard, B. Human and organisational factors in maritime accidents: Analysis of collisions at sea using the HFACS. Accid. Anal. Prev. 2013, 59, 26-37. [CrossRef] [PubMed]

2. Guedes Soares, C.; Teixeira, A.P. Risk assessment in maritime transportation. Reliab. Eng. Syst. Saf. 2001, 74, 299-309. [CrossRef]

3. Baniela, S.I.; Rios, J.V. Maritime Safety Standards and the Seriousness of Shipping Accidents. J. Navig. 2011, 64, 495-520. [CrossRef]

4. International Maritime Organization. Adoption of the Code of the International Standards and Recommended Practices for a Safety Investigation into a Marine Casualty or Marine Incident (Casualty Investigation Code); Resolution MSC.255(84); IMO: London, UK, 2008.

5. International Maritime Organization. Casualty_Related Matters; Reports on Marine Casualties and Incidents; MSC-MEPC.3/Circ.3; IMO: London, UK, 2008.

6. Baker, C.; McCafferty, D. Accident database review of human element concerns: What do the results mean for classification? In Proceedings of the International Conference Human Factors in Ship Design and Operation; RINA: London, UK, 2005.

7. Bielić, T.; Hasanspahić, N.; Čulin, J. Preventing marine accidents caused by technology-induced human error. Multidiscip. Sci. J. Marit. Res. 2017, 31, 33-37.

8. Bielić, T.; Čulin, J.; Poljak, I.; Orović, J. Causes of and Preventive Measures for Complacency as Viewed by Officers in Charge of the Engineering Watch. J. Mar. Sci. Eng. 2020, 8, 517. [CrossRef]

9. Erol, S.; Basar, E. The analysis of ship accident occurred in Turkish search and rescue area by using decision tree. Marit. Policy Manag. 2015, 42, 377-388. [CrossRef] 
10. Chen, S.-T.; Wall, A.; Davies, P.; Yang, Z.; Wang, J.; Chou, Y.-H. A Human and Organisational Factors (HOFs) analysis method for marine casualties using HFACS-Maritime Accidents (HFACS-MA). Saf. Sci. 2013, 60, 105-114. [CrossRef]

11. Schröder-Hinrichs, J.U.; Baldauf, M.; Ghirxi, K.T. Accident investigation reporting deficiencies related to organizational factors in machinery space fires and explosions. Accid. Anal. Prev. 2011, 43, 1187-1196. [CrossRef]

12. Qiao, W.; Liu, Y.; Ma, X.; Liu, Y. A methodology to evaluate human factors contributed to maritime accidents by mapping fuzzy FT into ANN based on HFACS. Ocean Eng. 2020, 107, 106892. [CrossRef]

13. Yildrim, U.; Başar, E.; Uğurlu, Ö. Assessment of collisions and grounding accidents with human factors analysis and classification system (HFACS) and statistical methods. Saf. Sci. 2019, 119, 412-425. [CrossRef]

14. Qiao, W.; Liu, Y.; Ma, X.; Liu, Y. Human Factors Analysis for Maritime Accidents Based on a Dynamic Fuzzy Bayesian Network. Risk Anal. 2020, 40, 957-980. [CrossRef]

15. Akyuz, E.; Celik, M.; Cebi, S. A phase of comprehensive research to determine marine-specific EPC values in human error assessment and reduction technique. Saf. Sci. 2016, 87, 63-75. [CrossRef]

16. Celik, M.; Cebi, S. Analytical HFACS for investigating human errors in shipping accidents. Accid. Anal. Prev. 2009, 41, 66-75. [CrossRef] [PubMed]

17. Chen, S.-T. An approach of identifying the common human and organisational factors (HOFs) among a group of marine accidents using GRA and HFACS-MA. J. Transp. Saf. Secur. 2019, 12, 1252-1294. [CrossRef]

18. Theophilus, S.C.; Esenowo, V.N.; Arewa, A.O.; Ifelebuegu, A.O.; Nnadi, E.O.; Mbanaso, F.U. Human factor analysis and classification system for the oil and gas industry (HFACS-OGI). Reliab. Eng. Syst. Saf. 2017, 167, 168-176. [CrossRef]

19. Chang, Y.H.; Wang, Y.C. Significant human risk factors in aircraft maintenance technicians. Saf. Sci. 2010, 48, 54-62. [CrossRef]

20. Reinach, S.; Viale, A. Application of a human error framework to conduct train accident/incident investigations. Accid. Anal. Prev. 2006, 38, 396-406. [CrossRef]

21. Celik, M.; Er, I.D. Identifying the Potential Roles of Design-based Failures on Human Errors in Shipboard Operations. TransnavInt. J. Mar. Navig. Saf. Sea Transp. 2007, 1, 339-343.

22. Scarborough, A.; Bailey, L.; Pounds, J. Examining ATC Operational Errors Using the Human Factors Analysis and Classification System (Report Number DOT/FAA/AM-05/25); Federal Aviation Administration, Office of Aerospace Medicine: Washington, DC, USA, 2005.

23. Ergai, A.; Cohen, T.; Sharp, J.; Wiegmann, D.; Gramopadhye, A.; Shappell, S. Assessment of the Human Factors Analysis and Classification System (HFACS): Intra-rater and inter-rater reliability. Saf. Sci. 2016, 82, 393-398. [CrossRef]

24. U.S DoD Human Factors Analysis and Classification System (HFACS) Version 7.0. Air Force Safety Center. Available online: https:/ / www.safety.af.mil/Portals/71/documents/Human\%20Factors/DoD\%20HFACS\%207.0\%20(AFSAS)\%20Final.pdf? ver=2019-06-06-110309-983 (accessed on 5 May 2020).

25. International Maritime Organization. Resolution A.884(21). Amendments to the Code for the Investigation of Marine Casualties and Incidents (Resolution A.849(20)); IMO: London, UK, 1999.

26. Batalden, B.-M.; Sydnes, A.K. Maritime safety and the ISM code: A study of investigated casualties and incidents. WMU J. Marit. Aff. 2014, 13, 3-25. [CrossRef]

27. Reason, J. Human Error; Cambridge University Press: New York, NY, USA, 1990; ISBN 0521314194.

28. Shappell, S.; Wiegmann, D. A Human Error Approach to Aviation Accident Analysis-The Human Factor Analysis and Classification System; Ashgate Publishing Ltd.: Aldershot, UK, 2003; ISBN 07546-1873-0.

29. Ćorović, B.; Djurović, P. Research of Marine Accidents through the Prism of Human Factors. Promet Traffic Transp. 2013, 25, 369-377.

30. Uyanik, G.K.; Güler, N. A study on multiple linear regression analysis. Procedia Soc. Behav. Sci. 2013, 106, 234-240.

31. Kloke, J.; McKean, J.W. Nonparametric Statistical Methods Using R; CRC Press, Taylor and Francis Group: Boca Raton, FL, USA, 2015; ISBN 13-978-1-4398-7344-1.

32. R-Project. Available online: https:/ / www.r-project.org/ (accessed on 20 April 2020).

33. Rothblum, A.M.; Wheal, D.; Withington, S.; Shappell, S.A.; Wiegmann, D.A.; Boehm, W.; Chaderjian, M. Human Factors in Incident Investigation and Analysis. In Proceedings of the 2nd International Workshop on Human Factors in Offshore Operations (HFW2002), Houston, TX, USA, 8-10 April 2002.

34. Smith, A.P.; Allen, P.H.; Wadsworth, E.M. A Comparative Approach to Seafarers' Fatigue 2007. In Proceedings of the International Symposium on Maritime Safety, Science and Environmental Protection, Athens, Greece, 10-11 May 2007.

35. Strauch, B. Can we examine safety culture in accident investigations, or should we? Saf. Sci. 2015, 77, 102-111. [CrossRef]

36. Kim, H.; Yang, C.-S.; Lee, B.-W.; Yang, Y.-H.; Hong, S. Alcohol effects on navigational ability using ship handling simulator. Int. J. Ind. Ergon. 2007, 37, 733-743. [CrossRef]

37. Oil Companies International Marine Forum. Guidelines for the Control of Drugs and Alcohol Onboard Ship; OCIMF: London, UK, 1995.

38. Oltedal, H.A. The use of safety management systems within the Norwegian tanker industry—Do they really improve safety. In Reliability, Risk and Safety: Theory and Applications; Bris, R., Guedes Soares, C., Martorell, S., Eds.; Taylor and Francis Group: London, UK, 2010; pp. 2355-2362. 
39. Vredenburgh, A.G. Organizational safety: Which management practices are most effective in reducing employee injury rates? J. Saf. Res. 2002, 33, 259-276. [CrossRef]

40. Oltedal, H.A.; Engen, O.A. Local management and its impact on safety culture and safety within Norwegian shipping. In Safety, Reliability and Risk Analysis: Theory, Methods and Applications; Martorell, S., Guedes Soares, C., Barnett, J., Eds.; Taylor and Francis Group: London, UK, 2009; pp. 1423-1430. 